\title{
Characteristic of Posterior Tibialis Tendon Dysfunction and Adult Acquired Flatfoot Deformity in Professional Athletes
}

\author{
Alfian Hasbi, Rosy Setiawati ${ }^{*}$, Paulus Rahardjo, Anggraini Dwi Sensusiati \\ alfianhasbi@gmail.com,dr_setia76@yahoo.co.id \\ ${ }^{a}$ Radiology Department, Faculty of Medicine, Universitas Airlangga, Surabaya, Indonesia \\ ${ }^{b}$ Musculoskeletal consultant, Radiology Department, Faculty of Medicine, Universitas Airlangga, Surabaya, Indonesia
}

\begin{abstract}
Flatfoot have many specific clinical symptom such as knee pain, back pain and foot pain. These pain rarely occur on babies and children, but the main cause of pain on runners and increase of sport injury. The purpose of this study was to identify characteristic posterior tibialis tendon dysfunction and adult acquired flatfoot deformity in professional athletes at East Java Indonesia. The sample consisted of 112 sample from 56 athletes $(n=112)$ with complain such as foot pain, and knee pain underwent foot ultrasound and radiographic examination in Radiology Department of Soetomo General Academic Hospital Surabaya. Flatfoot was found in 79 sample (70,5\%) while the other 33 sample $(29,5 \%)$. Tenosynovitis that diagnosed from thickening of posterior tibialis tendon sheath was found in 69 sample $(61,6 \%)$ and normal posterior tibialis tendon in 37 sample $(38,4 \%)$. Partial tear in posterior tibialis tendon was found in 7 sample $(6,3 \%)$, while the other 105 sample $(93,7 \%)$ are without tear. Type of sport that has the largest percentage of flatfoot was wrestling 24 (21,4\%) from all the sample. Most of the samples had bilateral flatfoot deformity $(92,8 \%)$ and bilateral posterior tibialis tendon dysfunction $(88,6 \%)$. In this study, amongst the athletes, the practitioners of wrestling and fencing had the largest number of flatfoot and tenosynovitis, whereas the largest percentage is gymnastics. The practitioners of wushu had the largest number and percentage of normal pedis radiographic $\mathrm{x}$-ray and posterior tibialis tendon ultrasound. Majority of athletes had flatfoot deformity and posterior tibialis tendon dysfunction, however only a few that had partial tear in posterior tibialis tendon.
\end{abstract}

Published by IJRP.ORG. Selection and/or peer-review under responsibility of International Journal of Research Publications (IJRP.ORG)

Keywords: Posterior tibialis tendon dysfunction, Adult acquired flatfoot deformity, ultrasound, radiographic x-ray, tenosynovitis, tear

\section{Introduction}

Our body were supported by the foot to make biomechanic movement from static to dynamic. This function of the foot because of the architecture that created from system of transverse and longitudinal arches (Lichota, M., Plandowska, M. and Mil, P., 2013). There have been many risk factors that caused adult acquired flatfoot deformity such as trauma, inflammatory arthritis, neuromuscular disease but the most common is posterior tibialis tendon dysfunction (Abousayed, M.M., Alley, M.C., Shakked, R. and Rosenbaum, A.J., 2017). To establish diagnosis of adult acquired flatfoot deformity radiographic x-ray is a gold standart, however to evaluate tendon, soft-tissue and ligament, ultrasound is very specific and 
sensitive to determine tenosynovitis, tendinosis as well as tear (Flores, D.V., Mejía Gómez, C., Fernández Hernando, M., Davis, M.A. and Pathria, M.N., 2019)

The main clinical complaint of flatfoot are knee pain, postural disturbance, foot pain and back pain, it usually appears at type of sports that mainly use foot to do the exercise (Kumala, M.S., Tinduh, D. and Poerwandari, D., 2019). The purpose of this study was to identify characteristic posterior tibialis tendon dysfunction and adult acquired flatfoot deformity in professional athletes at East Java Indonesia.

\section{Method}

\subsection{Subjects}

The sample consisted of 112 sample from 56 athletes $(\mathrm{n}=112)$ with complain such as foot pain, and knee pain underwent foot ultrasound and radiographic examination in Radiology Department of Soetomo General Academic Hospital Surabaya. The participants were professional athletes at East Java Indonesia. The inclusion criteria were athlete with foot pain, knee pain, back pain and postural disturbance. The exclusion criteria were history of ankle or pedis fracture, history of surgery for flatfoot.

This study was approved in Ethics Committee of Soetomo General Academic Hospital, Surabaya (2043/118/KEPK/III/2020).

\subsection{Ultrasound and Radiography $x$-ray}

Weight-bearing radiographs of the foot and ankle remain the gold standard for the diagnosis of adult-acquired flatfoot deformity (Abousayed, M.M., Alley, M.C., Shakked, R. and Rosenbaum, A.J., 2017). Calcaneal inclination angle is one of the most common measurement to make diagnosis for flatfoot deformity (Flores, D.V., Mejía Gómez, C., Fernández Hernando, M., Davis, M.A. and Pathria, M.N., 2019) Measurement of calcaneal inclination angle is an angle between the line at the plantar calcaneal surface and the horizontal plane (Fig. 1). Allignment angle (degrees) $<18^{\circ}$ is pes planus.

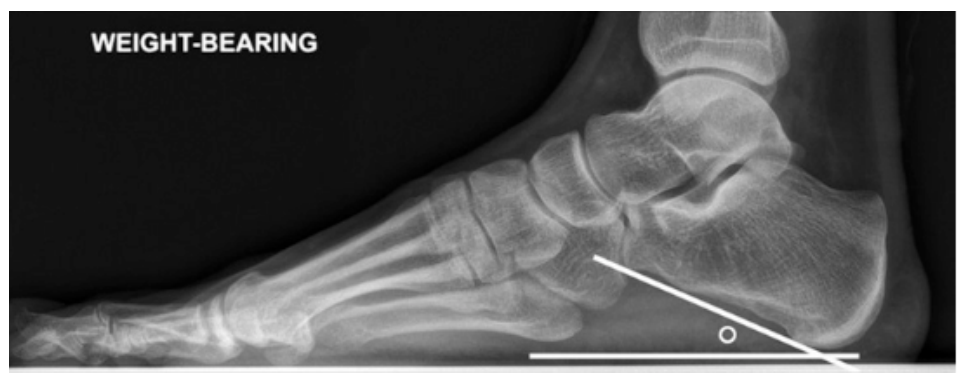

Figure 1. Lateral radiograph shows the calcaneal inclination angle (Flores, D.V., Mejía Gómez, C., 2019)

Posterior tibialis dysfunction appeared as tenosynovitis, tear or tendinosis. Free fluid collection that make hypoechoic lesion around posterior tibialis tendon was tenosynovitis (hyperechoic central structure with a hypoechoic halo) on the ultrasound transverse position (Fig. 2). Posterior tibialis tendon tear or rupture appeared from ultrasound as a empty tibial groove and have a gap intermuscular of posterior tibialis tendon (Hsu, T.C., Wang, C.L., Wang, T.G., Chiang, I.P. and Hsieh, F.J., 1997) (Fig. 3). 


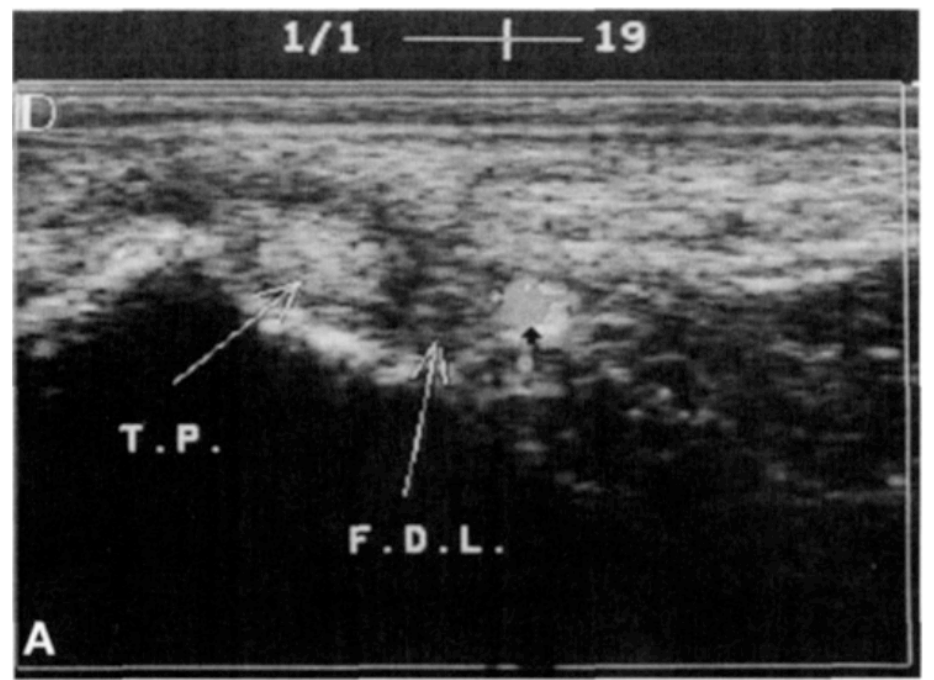

Figure 2. Transverse sonographic of posterior tibialis tendon with tenosynovitis (Hsu, T.C., Wang, C.L., Wang, T.G.,1997)

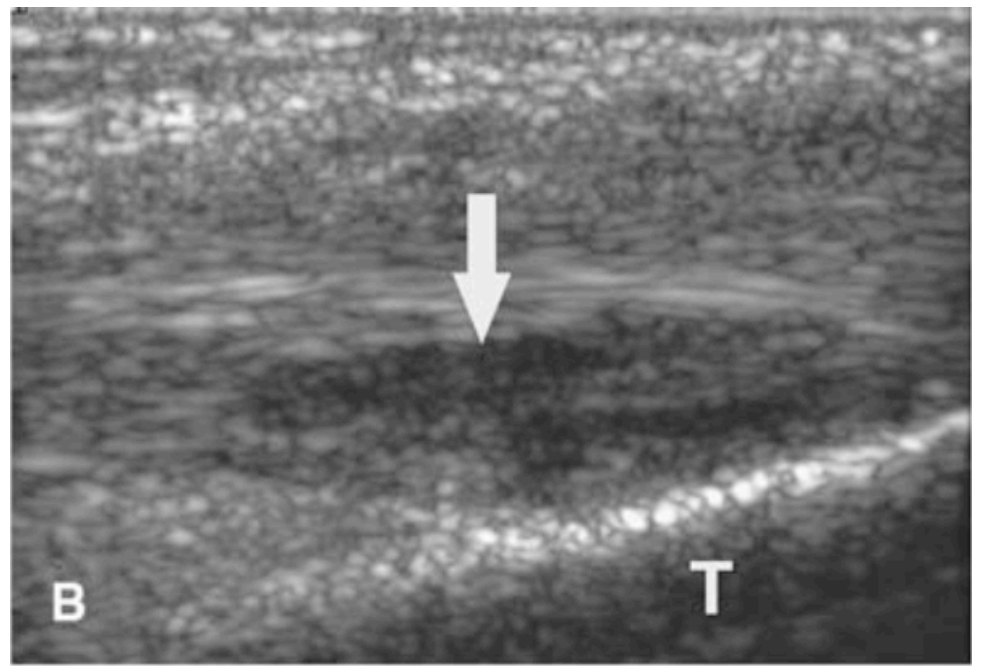

Figure 3. Longitudinal sonographic of posterior tibialis tendon with partial tear (Nallamshetty, L., Nazarian, L.N., 2005

\subsection{Statistical Analysis}

We use SPSS 24 software (IBM, Armonk, New York, United States) for statistical analysis. Data from questionnaire, ultrasound and, radiographic x-ray were arranged in table and analyzed.

\section{Results}

The final sample sizes that met the inclusion and, exclusion criteria was 112 sample. Flatfoot was found in 79 sample (70,5\%) while the other 33 sample (29,5\%) (Table.1). Tenosynovitis that diagnosed from thickening of posterior tibialis tendon sheath was found in 69 sample $(61,6 \%)$ and normal posterior tibialis tendon in 37 sample (38,4\%) (Table. 2). Partial tear in posterior tibialis tendon was found in 7 samples $(6,3 \%)$, while the other 105 samples $(93,7 \%)$ are without tear 
(Table. 3). Type of sport that has the largest percentage of flatfoot was wrestling $24(21,4 \%)$ from all the sample (Table. 4). Most of the samples has bilateral flatfoot deformity (92,8\%) (Table. 5) and bilateral posterior tibialis tendon dysfunction $(88,6 \%)$ (Table. 6). Only a very few samples has unilateral flatfoot deformity and unilateral posterior tibialis tendon dysfunction (Table.7).

Table 1. Radiographic evaluation with calcaneal inclination angle

\begin{tabular}{ccc}
\hline Radiographic & $\mathrm{n}$ & $\%$ \\
\hline Flatfoot & 79 & $70,5 \%$ \\
Normal & 33 & $29,5 \%$ \\
\hline
\end{tabular}

Table 2. Ultrasound evaluation for tendon sheath of posterior tibialis tendon

\begin{tabular}{ccc}
\hline $\begin{array}{c}\text { Tendon sheath of PTT } \\
(>7 \mathrm{~mm})\end{array}$ & $\mathrm{n}$ & $\%$ \\
\hline Thickening & 69 & $61,6 \%$ \\
Normal & 43 & $38,4 \%$ \\
\hline
\end{tabular}

Table 3. Ultrasound evaluation for tendon sheath of posterior tibialis tendon

\begin{tabular}{ccc}
\hline $\begin{array}{c}\text { Tear of posterior tibialis } \\
\text { tendon }\end{array}$ & $\mathrm{n}$ & $\%$ \\
\hline Partial tear & 7 & $6,3 \%$ \\
Normal & 105 & $93,7 \%$
\end{tabular}

Table 4. Type of sport, ultrasound and radiographic x-ray evaluation

\begin{tabular}{ccccccc}
\hline Type of sports & $\begin{array}{c}\text { Normal } \\
\text { ultrasound (\%) }\end{array}$ & $\begin{array}{c}\text { Tenosynovitis } \\
(\%)\end{array}$ & Tear (\%) & $\begin{array}{c}\text { Normal } \\
\text { radiographic x- } \\
\text { ray (\%) }\end{array}$ & Flatfoot (\%) & n \\
\hline Athletics & $6(5,36 \%)$ & $8(7,1 \%)$ & $1(0,9 \%)$ & $5(4,5 \%)$ & $9(8 \%)$ & 14 \\
Wrestling & $10(8,9 \%)$ & $24(21,4 \%)$ & $2(1,8 \%)$ & $10(8,9 \%)$ & $24(21,4 \%)$ & 34 \\
Handball & $10(8,9 \%)$ & $10(8,9 \%)$ & $1(0,9 \%)$ & $7(6,25 \%)$ & $13(11,65 \%)$ & 20 \\
Fencing & $8(7,1 \%)$ & $18(16,1 \%)$ & $2(1,8 \%)$ & $4(3,6 \%)$ & $22(19,6 \%)$ & 26 \\
Wushu & $9(8,14 \%)$ & $5(4,5 \%)$ & $1(0,9 \%)$ & $7(6,25 \%)$ & $7(6,25 \%)$ & 14 \\
Gymnastics & $0(0 \%)$ & $4(3,6 \%)$ & $0(0 \%)$ & $0(0 \%)$ & $4(3,6 \%)$ & 4 \\
Total & $43(38.4 \%)$ & $69(61,6 \%)$ & $7(6,3 \%)$ & $33(29,5 \%)$ & $79(70,5 \%)$ & 112 \\
\hline
\end{tabular}


Table 5.The characteristic of flatfoot group

\begin{tabular}{cc}
\hline Side of Flatfoot & Sum (\%) \\
\hline Right foot & $2(2,9 \%)$ \\
Left foot & $3(4,3 \%)$ \\
Both sides & $64(92,8 \%)$ \\
Total & $69(100 \%)$ \\
\hline
\end{tabular}

Table 6. The characteristic of Tenosynovitis group

\begin{tabular}{cc}
\hline Side of Flatfoot & Sum (\%) \\
\hline Right foot & $5(6,3 \%)$ \\
Left foot & $4(5,1 \%)$ \\
Both sides & $70(88,6 \%)$ \\
Total & $79(100 \%)$ \\
\hline
\end{tabular}

Table 7. The characteristic of posterior tibialis tendon tear

\begin{tabular}{cc}
\hline Side of Flatfoot & Sum (\%) \\
\hline Right foot & $6(85,7 \%)$ \\
Left foot & $1(14,3 \%)$ \\
Both sides & 0 \\
Total & $7(100 \%)$ \\
\hline
\end{tabular}

\section{Discussion}

The foot was mainly supported by posterior tibialis tendon to maintain medial longitudinal arch and balancing the hindfoot against valgus deformity. Accordingly adult acquired flatfoot deformity can be caused by posterior tibialis tendon dysfunction. Posterior tibialis tendon dysfunction manifestation given an overview in the form of tendinosis, tenosynovitis, and tear. When the person got posterior tibialis tendon dysfunction, the body weight distribution will be disturbed to the supporting structures, consisting of spring ligamentum complex, sinus tarsi ligament, and deltoid ligament complex. Distribution from this structure can caused flatfoot deformity (Lin, Y.C., Mhuircheartaigh, J.N., Lamb, J., Kung, J.W., Yablon, C.M. and Wu, J.S., 2015).

This study showed that's the majority of athletes have flatfoot deformity and posterior tibialis tendon tenosynovitis. These results are correlated with previous studies Lichota et al that the majority of sportsmen especially in athletics have flatfoot deformity. Research on the variability of foot-arches amongst practitioners of different sporting has already been carried out by Nizankowski and Wanke, found that the greatest risk factor for the diagnosis of flatfoot and posterior tibial tendon dysfunction occurs in sports athletes.( Michelson, J.D., Durant, D.M. and McFarland, E., 2002) Author also found only very few athletes $(6,3 \%)$ that have tear at posterior tibialis tendon this have a different results from previous studies by Hsu, T.C., Wang which had (43,75\%) from total sample. 
The sport that has the greatest number and greatest percentage of flatfoot is wrestling. These finding were similar with previous study by Mira Saraswati Kumala with resulted in the top three largest sport that is related to flatfoot deformity including sepak takraw, athletic and wrestling. From the table no 5 and 6 conclude that characteristic of flatfoot and tenosynovitis most likely bilateral foot and only very few sample that only had unilateral flatfoot or unilateral tenosynovitis. This findings are concordance with previous study by Mira Saraswati Kumala that only (14,3\%) have unilateral flatfoot.

Author have opinion that this research could be very useful to make better analyze study to understand more about risk factor and type of sports that have more predispotition to increase the chance of being flatfoot deformity and posterior tibialis tendon dysfunction. Limitation of the study were the amount of the sample which are only limited variety of the branch of sports.

\section{Conclusion}

Posterior tibialis tendon plays an important role in dynamic support of arch. This study conducted that there is a close relation between posterior tibialis tendon dysfunction, flatfoot deformity in professional athletes, that posterior tibialis tendon dysfunction is common cause of acquired flatfoot deformity. A compressive understanding of posterior tibialis tendon dysfunction and flatfoot diagnosis will lead to more effective management in reducing the symptom.

\section{Acknowledgment}

A sincere gratitude to all my teachers, colleagues, family, and all the patients included in this study.

\section{References}

Lichota, M., Plandowska, M. and Mil, P., 2013. The arches of the feet of competitors in selected sporting disciplines. Polish Journal of Sport and Tourism, 20(2), pp.135-140.

Abousayed, M.M., Alley, M.C., Shakked, R. and Rosenbaum, A.J., 2017. Adult-acquired flatfoot deformity: etiology, diagnosis, and management. JBJS reviews, 5(8), p.e7.

Flores, D.V., Mejía Gómez, C., Fernández Hernando, M., Davis, M.A. and Pathria, M.N., 2019. Adult acquired flatfoot deformity: Anatomy, biomechanics, staging, and imaging findings. RadioGraphics, 39(5), pp.1437-1460.

Kumala, M.S., Tinduh, D. and Poerwandari, D., 2019. Comparison of Lower Extremities Physical Performance on Male Young Adult Athletes with Normal Foot and Flatfoot. Surabaya Physical Medicine and Rehabilitation Journal, 1(1), pp.6-13.

Hsu, T.C., Wang, C.L., Wang, T.G., Chiang, I.P. and Hsieh, F.J., 1997. Ultrasonographic examination of the posterior tibial tendon. Foot \& ankle international, $18(1)$, pp.34-38.

Sivachandiran, S. and Kumar, G., 2016. Effect of corrective exercises programme among athletes with flat feet on foot alignment factors. International Journal of Physical Education, Sports and Health, 3(6), pp.193-196.

Michelson, J.D., Durant, D.M. and McFarland, E., 2002. The injury risk associated with pes planus in athletes. Foot \& ankle international, 23(7), pp.629633.

Nallamshetty, L., Nazarian, L.N., Schweitzer, M.E., Morrison, W.B., Parellada, J.A., Articolo, G.A., Rawool, N.M. and Abidi, N.A., 2005. Evaluation of posterior tibial pathology: comparison of sonography and MR imaging. Skeletal radiology, 34(7), pp.375-380.

Lin, Y.C., Mhuircheartaigh, J.N., Lamb, J., Kung, J.W., Yablon, C.M. and Wu, J.S., 2015. Imaging of adult flatfoot: correlation of radiographic measurements with MRI. American Journal of Roentgenology, 204(2), pp.354-359.

Karasick, D. and Schweitzer, M.E., 1993. Tear of the posterior tibial tendon causing asymmetric flatfoot: radiologic findings. AJR. American journal of roentgenology, 161(6), pp.1237-1240.

Ikoma, K., Ohashi, S., Maki, M., Kido, M., Hara, Y. and Kubo, T., 2016. Diagnostic Characteristics of Standard Radiographs and Magnetic Resonance Imaging of Ruptures of the Tibialis Posterior Tendon. The Journal of Foot and Ankle Surgery, 55(3), pp.542-546.

Younger, A.S., Sawatzky, B. and Dryden, P., 2005. Radiographic assessment of adult flatfoot. Foot \& ankle international, $26(10)$, pp.820-825.

Nizankowski Cz., Wanke A. (1967). Variation in the arches of the foot of competitors in selected sporting disciplines. 